\title{
PENGARUH PERAWATAN RUTIN BAYI BARU LAHIR TERHADAP KEBERHASILAN INISIASI MENYUSU DINI DI RUANG PONEK RSUD KABUPATEN JOMBANG
}

\author{
Rini Hayu Lestari \\ Sekolah Tinggi Ilmu Kesehatan Pemkab Jombang \\ Email: hanif_saify@yahoo.com
}

\begin{abstract}
Early initiation of breastfeeding today has become a new hope for the world of obstetrics as a life-saving alternative step mother and baby. However, in practice there are factors that lead to the failure to conduct such an early suckling insiasi implementation of routine care of the newborn. This study aims to determine the effect of routine newborn care to the success of early initiation of breastfeeding in hospitals PONEK Jombang whose implementation. This study used the Analytic korelastional research with cross sectional method. The population in this study were newborn babies born in hospitals PONEK Lounge Jombang and using purposive sampling the treated sample obtained all newborns vaginal qualified IMD and do not do routine maintenance BBL according to the stages. The results showed that the influence of routine maintenance There newborn to suckle Early initiation success in PONEK Hospital Jombang on April 27 to June 6, 2015. Concluded there is the influence of routine newborn care to the success of Early Initiation of Breastfeeding. From these results, health workers must increase efforts to prevent maternal deaths, childbirth, postpartum and improvement of maternal and child health programs.
\end{abstract}

\section{Keywords: Routine Newborn Care, Success Early Initiation of Breastfeeding (IMD)}

\begin{abstract}
Abstrak: Inisiasi menyusu dini dewasa ini telah menjadi harapan baru bagi dunia kebidanan sebagai alternative langkah penyelamatan kehidupan ibu dan bayi. Namun dalam pelaksanaannya terdapat faktor penghambat yang menyebabkan ketidakberhasilan pelaksanan insiasi menyusu dini diantaranya pelaksanaan perawatan rutin bayi baru lahir. Penelitian ini bertujuan untuk mengetahui pengaruh perawatan rutin bayi baru lahir terhadap keberhasilan inisiasi menyusu dini di Ponek RSUD Kabupaten Jombang yang pelaksanaannya. Penelitian ini menggunakan penelitian analitic korelastional dengan metode pendekatan cross sectional. Populasi dalam penelitian ini adalah bayi baru lahir yang dilahirkan di Ruang Ponek RSUD Kabupaten Jombang dan dengan menggunakan purposive sampling didapatkan sampel perlakuan yakni semua bayi baru lahir pervaginam yang memenuhi syarat IMD dan tidak dilakukan perawatan rutin BBL sesuai tahapan. Hasil penelitian menunjukkan bahwa Ada pengaruh perawatan rutin bayi baru lahir terhadap keberhasilan Inisiasi Menyusu Dini di Ponek RSUD Kabupaten Jombang pada tanggal 27 April - 6 Juni 2015. Disimpulkan ada pengaruh perawatan rutin bayi baru lahir terhadap keberhasilan Inisiasi Menyusu Dini. Dari hasil tersebut petugas kesehatan harus lebih meningkatkan upaya pencegahan kematian ibu hamil, bersalin, nifas dan peningkatan program kesehatan ibu dan anak.
\end{abstract}




\section{Kata kunci : Perawatan Rutin Bayi Baru Lahir, Keberhasilan Inisiasi Menyusu Dini (IMD)}

\section{PENDAHULUAN}

Inisiasi Menyusu Dini atau disingkat sebagai IMD merupakan program yang sedang gencar dianjurkan pemerintah. Inisiasi menyusu dini dewasa ini telah menjadi harapan baru bagi dunia kebidanan sebagai alternative langkah penyelamatan kehidupan ibu dan bayi karena manfaatnya yang begitu besar antara lain merangsang kontraksi otot rahim sehingga mengurangi resiko perdarahan ibu sesudah melahirkan, mempertahankan suhu bayi tetap hangat serta diperolehnya kolostrum yang sangat bermanfaat bagi system kekebalan tubuh bayi.

Program ini mempunyai manfaat yang besar untuk bayi maupun sang ibu yang baru melahirkan. Tetapi, kurangnya pengetahuan dari orang tua, pihak medis maupun keengganan untuk melakukannya membuat Inisiasi Menyusu Dini masih jarang dipraktekkan. Banyak orang tua yang merasa kasihan dan tidak percaya seorang bayi yang baru lahir dapat mencari sendiri susu ibunya. Ataupun rasa malu untuk meminta dokter yang membantu persalinan untuk melakukannya.Begitu juga dengan dokter atau bidan yang tidak mau direpotkan dengan kegiatan ini sehingga akhirnya bayi tidak diberi kesempatan untuk melakukan ini.

Penelitian tentang Inisiasi Menyusu Dini telah banyak dilaksanakan diantaranya penelitian Dr.Keren Edmond (2006) di Ghana yang menyebutkan bahwa pada 11.000 kelahiran pada bulan juni
2013 sampai bulan juni 2004, setelaha diberikan kesempatan menyusu dalam satu jam pertama dapat menyelamatkan $22 \%$ bayi di bawah umur 28 hari dan 8 kali lebih berhasil dalam pemberian ASI eksklusif (Utami, 2010). Penelitian lain juga menyebutkan bahwa baru $18,18 \%$ yang melakukan IMD (Rahmi, 2008). Keterangan di atas dapat disimpulkan bahwa pelaksanaan program Inisiasi Menyusu Dini di Indonesia secara umumnya sedikit dilaksanakan (Wahdah, 2009).

Keberhasilan pelaksanaan inisiasi menyusu dini dipengaruhi oleh beberappa factor pendukung dan penghambat yang terjadi ketika proses persalinan berlangsung. Salah satu factor penghambat yang menyebabkan ketidakberhasilan pelaksanaan inisiasi menyusu dini adalah pelaksanaan perawatan rutin bayi baru lahir.

Latar belakang diatas membuat peneliti tertarik untuk meneliti pengaruh perawatan rutin bayi baru lahir terhadap keberhasilan inisiasi menyusu dini.

\section{METODE}

Jenis penelitian yang dilakukan merupakan penelitian analitic korelastional dengan menggunakan metode pendekatan cross sectional. Penelitian ini dilaksanakan di Ruang Ponek RSUD Jombang pada tanggal 27 April - 6 Juni 2015.

Peneliti melakukan observasi menggunakan checklist untuk menilai keberhasilan pelaksanaan inisiasi menyusu dini pada kelompok 
sampel. Setelah didapatkan data dari responden, peneliti melakukan langkah analisis data yakni editing, coding, scoring, tabulating serta analisis univariat dan bivariat untuk interpretasi hasil penelitian.

Dalam melakukan penelitian ini peneliti mendapatkan ijin penelitian dari Institusi STIKES Pemkab Jombang, kemudian surat ijin tersebut diajukan kepada RSUD Jombang. Setelah mendapat surat balasan dari RSUD Jombang, surat balasan tersebut di ajukan ke Ruang Ponek RSUD Jombang. Setelah mendapat ijin dari Kepala Ruang Ponek RSUD Jombang kemudian peneliti mengumpulkan data dan melakukan pendekatan kepada responden dengan terlebih dahulu menjelaskan maksud dan tujuan penelitian yang akan dilakukan oleh peneliti, memberikan informed consent dan melakukan observasi.

Setelah data terkumpul, maka dilakukan pengolahan data melalui tahapan Editing, Coding, dan Tabulating.

\section{HASIL \& PEMBAHASAN}

\section{a.Hasil}

\section{Univariat}

Tabel 4.1 Data Tabulasi Perawatan Rutin BBL

\begin{tabular}{|c|l|c|c|}
\hline No & Karakteristik & $\mathrm{F}$ & $\begin{array}{c}\text { Prosentase } \\
(\%)\end{array}$ \\
\hline 1 & $\begin{array}{l}\text { Dilakukan } \\
\text { penundaan } \\
\text { perawatan } \\
\text { rutin BBL }\end{array}$ & 71 & 84.52 \\
\hline 2 & $\begin{array}{l}\text { Tidak } \\
\text { dilakukan } \\
\text { perawatan } \\
\text { rutin BBL }\end{array}$ & 13 & 15.48 \\
\hline & Jumlah & 84 & 100.00 \\
\hline
\end{tabular}

Sumber : Data Primer Tahun 2015

Dari tabel 4.1 di atas menunjukkan bahwa dari 84 responden hampir seluruhnya sebanyak 71 orang $(84,52 \%)$ dilakukan penundaan perawatan rutin pada Bayi Baru Lahir.

Tabel 4.2 Data Tabulasi IMD (Inisiasi Menyusu Dini)

\begin{tabular}{|c|l|c|c|}
\hline No & Karakteristik & F & $\begin{array}{c}\text { Prosentase } \\
(\%)\end{array}$ \\
\hline 1 & $\begin{array}{l}\text { Tidak berhasil } \\
\text { dilakukan IMD }\end{array}$ & 40 & 47.62 \\
\hline 2 & Berhasil dil & 44 & 52.38 \\
\hline & Jumlah & 84 & 100.00 \\
\hline
\end{tabular}

Sumber : Data Primer Tahun 2015

Dari tabel 4.2 di atas menunjukkan bahwa dari 84 responden sebagian besar sebanyak 44 orang $(52,38 \%)$ berhasil dilakukan IMD (Inisiasi Menyusu Dini).

\section{Bivariat}

Tabel 4.3 Chisquare Test

\begin{tabular}{|c|l|c|c|c|}
\hline No & Jenis Test & Value & Df & $\begin{array}{c}\text { Asymp.sig } \\
\text { (2-sided) }\end{array}$ \\
\hline 1 & $\begin{array}{l}\text { Person Chi- } \\
\text { square Test }\end{array}$ & 8,44 & & 0,04 \\
\hline
\end{tabular}

Sumber : Data Primer Tahun 2015

Dari tabel 4.3 di atas menunjukkan bahwa nilai $\dot{\rho}<\alpha$ $(0,05)$ sehingga ada hubungan antara perawatan rutin Bayi baru Lahir dengan keberhasilan IMD (Inisiasi Menyusu Dini).

\section{Multivariat}

Tabel 4.4 Tabulasi silang antara Pengaruh Perawatan Rutin BBL dengan Keberhasilan IMD di Ruang PONEK RSUD Kabupaten Jombang

\begin{tabular}{|c|c|c|c|c|c|c|c|}
\hline \multirow{2}{*}{ No } & \multirow{2}{*}{$\begin{array}{c}\text { Perawatan } \\
\text { Rutin } \\
\text { BBL }\end{array}$} & \multicolumn{3}{|c|}{$\begin{array}{c}\text { Dilakukan IMD } \\
\text { Tidak } \\
\text { berhasil }\end{array}$} & \multicolumn{2}{|c|}{ Berhasil } & \multicolumn{2}{|c|}{ Jumlah } \\
\cline { 3 - 7 } 1 & $\begin{array}{l}\text { Dilakukan } \\
\text { penundaan }\end{array}$ & 29 & 34.52 & 42 & 50 & 71 & 100 \\
\hline 2 & $\begin{array}{l}\text { Tidak } \\
\text { dilakukan } \\
\text { penundaan }\end{array}$ & 11 & 13.10 & 2 & 2.38 & 13 & 100 \\
\hline \multicolumn{2}{|l|}{ Jumlah } & 40 & 47.62 & 44 & 52.38 & 84 & 100 \\
\hline
\end{tabular}




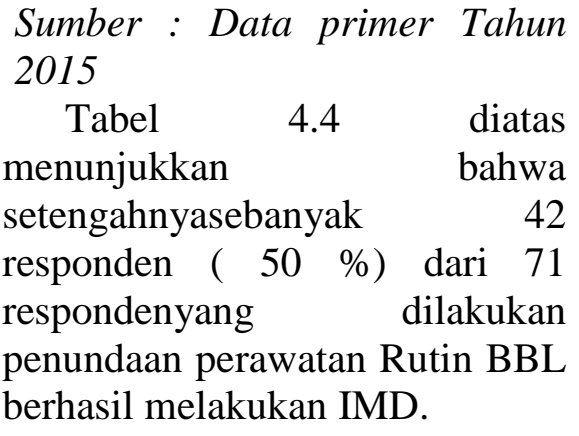

\section{b. Pembahasan}

Dari tabel 4.1 di atas menunjukkan bahwa dari 84 responden hampir seluruhnya sebanyak 71 orang $(84,52 \%)$ dilakukan penundaan perawatan rutin pada Bayi Baru Lahir.

Berdasarkan hasil penelitian menunjukkan bahwa hampir seluruhnya dilakukan penundaan perawatan rutin pada bayi baru lahir. Hal ini disebabkan karena Bayi baru lahir harus segera dilakukan IMD (Inisiasi menyusu Dini) dimana bayi dibiarkan mencari putting susu ibunya sendiri yang mempunyai manfaat untuk meningkatkan hubungan khusus ibu dan bayi (Maryunani, 2012). Segera setelah bayi lahir, setelah tali pusat dipotong, letakkan bayi tengkurap diperut ibu dengan kulit bayi kontak dengan kulit ibu, Biarkan kontak kulit ke kulit ini menetap selama setidaknya 1 jam bahkan lebih sampai bayi dapat menyusu sendiri. Bayi diberi topi dan diselimuti (JNPK-KR Indonesia, 2008).

Dari tabel 4.2 di atas menunjukkan bahwa dari 84 responden sebagian besar sebanyak 44 orang $(52,38 \%)$ berhasil dilakukan IMD (Inisiasi Menyusu Dini).

Keberhasilan melakukan IMD (Inisiasi Menyusu Dini) dipengaruhi oleh beberapa faktor, antara lain : Pemberian informasi pada ibu oleh petugas kesehatan, pengadaan pelatihan kepada tenaga kesehatan untuk melakukan IMD, Memberikan informasi ke seluruh ibu hamil tentang keuntungan dan pengelolaan pemberian ASI saat pemeriksaan ANC, Membantu ibu dalam pemberian ASI sesegera mungkin setelah persalinan, Menunjukkan pada ibu cara menyusui, dan bagaimana menjaga proses laktasi bila terpisah dari bayinya, Tidak memberikan bayi baru lahir makanan atau minuman selain ASI, tidak menggunakan alat bantu dalam pemberian ASI. Dari beberapa faktor tersebut, maka dapat mempengaruhi keberhasilan IMD (Inisiasi menyusu Dini).

$\begin{array}{llr}\begin{array}{c}\text { Pada Tabel } \\ \text { menunjukkan }\end{array} & \begin{array}{r}\text { diatas } \\ \text { bahwa }\end{array} \\ \text { setengahnyasebanyak } & 42 \text { responden }(\end{array}$
$50 \%$ ) dari 71 responden yang dilakukan penundaan perawatan Rutin BBL berhasil melakukan IMD.

Menunda melakukan perawatan rutin misalnya dengan menunda memandikan bayi berarti menghindarkan hilangnya panas badan bayi.Selain itu, kesempatan vernix meresap, melunakkan dan melindungi kulit bayi lebih besar.Bayi dapat dikeringkan segera setelah bayi lahir.Penimbangan dan pengukuran dapat ditunda sampai menyusu awal selesai (Utami, 2010). Inisiasi menyusui dini (IMD) dikatakan berhasil apabila bayi dapat menyusu segera setelah lahir dengan usaha sendiri selama \pm 1 jam (Yuliarti, 2010).

Dari hasil data statistic pada table 4.3, didapatkan hasil bahwa ada pengaruh perawatan rutin bayi baru lahir terhadap keberhasilan Inisiasi Menyusu Dini di Ponek RSUD Kabupaten Jombang pada bulan April - Mei 2015. Hal ini dikarenakan keberhasilan dalam 
IMD (Inisiasi Menyusu Dini) dilakukan segera setelah lahir setidaknya 1 jam (Suryani, 2011) yang dipengaruhi oleh beberapa faktor antara lain dengan penundaan perawatan rutin bayi baru lahir.

\section{KESIMPULAN}

\section{Kesimpulan}

1. Hampir seluruhnyadari 84 responden dilakukan penundaan perawatan rutin pada Bayi Baru Lahir sebanyak 71 orang $(84,52 \%)$

2. Sebagian besar dari 84 responden berhasil dilakukan IMD (Inisiasi Menyusu Dini) sebanyak 44 orang $(52,38 \%)$

3. Ada hubungan antara perawatan rutin Bayi baru Lahir dengan keberhasilan IMD (Inisiasi Menyusu Dini) dengan Uji Chisquare nilai 0,04 yang menunjukkan kurang dari $<\alpha$ $(0,05)$

4. Pengaruh antara perawatan rutin Bayi baru Lahir dengan keberhasilan IMD (Inisiasi Menyusu Dini) dengan Uji T Test

\section{Saran}

\section{Bagi Teori}

Dengan adanya hasil penelitian diharapkan dapat membuktikan kesesuaian kajian teori dengan variabel yang diteliti.

\section{Bagi Praktisi}

Dengan adanya hasil penelitian ini diharapkan bisa dijadikan masukan bagi perumus kebijakan khususnya dalam upaya pencegahan kematian ibu hamil, bersalin, nifas dan peningkatan program kesehatan ibu dan anak.

\section{DAFTAR PUSTAKA}

Ambarwati, dkk. 2010. Asuhan Kebidanan Nifas. Yogyakarta : Numed.

Behrman, R.E. dkk. 2000. Ilmu Kesehatan Anak Nelson. Volume 1. Diterjemahkan oleh A.Samik Wahab.Jakarta : EGC

Berkat, Satrinawati dan Rosnah Sutan. 2014. The Effect of Early Initiation of Breastfeeding on Neonatal Mortality among Low Birth Weight in Aceh Province, Indonesia : An Unmatched Case Controlo Study. Hindawi Publishing Corporation.Volume 2014.

Bobak,dkk.2009.Buku Keperawatan Maternitas, Jakarta: EGC

Carpenito, L.J. 2009. Buku Saku Diagnosa Keperawatan. Jakarta : EGC

DepKes. 2007. Pelayanan Kesehatan Neonatal Esensial. Jakarta : DepKes.RI

DepKes. 2008. Pelayanan Kesehatan Neonatal Esensial. Jakarta : DepKes RI.

Exavery, Amon, dkk. 2015. Determinants of early initiation of breastfeeding in rural Tanzania. International Breastfeeding Journal.

Himani, dkk. 2011. Effect of Initiation of breast - feeding within one hour of the delivery on 'maternal - infant bonding. Nursing and Midwifery Journal, Vol. 7 No. 3.

Indonesia. 2013. Departemen Kesehatan. Laporan Hasil Riset Kesehatan Dasar (Riskesdas ) indonesia. Jakarta : Badan Litbang Kesehatan.

JNPK-KR. 2008. Asuhan Persa Normal. DepKes RI.

Khanal, Vishnu.dkk. 2015. Factors Associated with Early Unitiation of Breastfeeding in Western 
Nepal. Environmental Research and Public Health. ISSN 1660 4601.

Kementrian Kesehatan RI. Petunjuk Teknis Bantuan Operasional Kesehatan, kementrian Kesehatan RI, 2011.

Lau, Ying, dkk. Maternal, Infant Characteristics, Breastfeeding Technique, and Initiation : Structural Equation Modeling Approaches

Ladewig, et al. 2006. Clinical handbook : contemporary maternal - newborn nursing care, $5^{\text {th }}$ ed. ; alih bahasa, salmiyatun ; editor edisi bahasa indonesia, Ramonica Patricia Kapoh. Jakarta : EGC.

Mochtar, R. 2011. Sinopsis Obstetri Jilid 2. Jakarta: EGC.

Muslihatun. 2010. Asuhan Neonatus bayi baru lahir. Jakarta : Buku kedokteran EGC

Nursalam. 2013. Metodelogi Penelitian Ilmu Keperawatan Edisi 3. Jakarta : Salemba Medika.

Orun, Emel., dkk. 2010. Facto. Associated with Breastfeeding Initiation rime in a Baby Friendly Hospital. The Turkist Journal of Pediatrics $52: 10-16$.

Pernasia. 2010. program manajemen laktasi. Jakarta : Bina Rupa Aksara

Profil Kesehatan Dinas Kesehatan Kabupaten Jombang,2013

Queensland Maternity and Neonatal Clinical Guideline. 2010. Breastfeeding Initiation

Saifudin. 2010. Buku Panduan Praktis Pelayanan Kesehatan Maternal dan Neonatal. Jakarta : PT Bina Pustaka Sarwono Prawirohardjo
Tom and Avroy A. Fanaroff. 2008. At a Glance neonatologi. Jakarta : Erlangga

Utami, R. 2010. Inisiasi menyusu dini plus ASI eksklusif. Jakarta : Pustaka bunda

WHO Secretariat. 2010. Early Initation of Breastfeeding :The Key to Survival and Beyond.

Widiastuti, Yuni Puji, dkk..2013.Faktor-Faktor Yang Mempengaruhi Pelaksanaan Inisiasi Menyusu Dini di Ruang Mawar Rumah Sakit Umum Daerah Dr. H. Soewondo Kendal. Jurnal Keperawatan Maternitas. Volume 1, No.2. 